\section{Amiebenomo OM Achugwo DC Abah I}

DOI:http://dx.doi.org/10.4314/njp.v43i3.11

Accepted: 17th December 2015

Onyekachukwu MA（邓)

Abah I

Department of optometry,

Faculty of Life Sciences

University of Benin, Benin-City

Email:

maryanne.amiebenomo@uniben.edu.ng

Achugwo DC

Asmara college of Health Sciences, Asmara, Eritrea.

\title{
Parental knowledge and attitude to children's eye care services
}

\begin{abstract}
Background: The early years of life is very significant in the development of the eyes and vision, any disruption at this stage may lead to severe visual impairment or even blindness. Eye examination and treatment of children is not just a right of the child, but also a necessity to properly monitor and evaluate the eyes and visual structure. The responsibility to make decisions as regards eye care of a child lies on the parents or guardian.
\end{abstract}

Purpose: To find out parents knowledge and attitude towards eye examination and treatment for their children and the effect of demographic factors such as gender, age, educational status and number of children.

Method: A total of 468 parents including fathers and mothers (not necessarily couples) in Benin City participated in this cross-sectional observational study. A semistructured questionnaire seeking parents' demographic characteristics, attitude towards eye examination and treatment, factors affecting the need for routine eye checkup for their children and parents' knowledge about the eyes was used. The data was analyzed using SPSS. The test of significance was performed using Chi square and significance was taken at $\mathrm{p}<0.05$.

Results: Only gender affected parents' attitude towards eye examination for their children $(p=0.003)$. There were no significant associations between parents' attitude to eye care and age, educational status and number of children for both fathers and mothers. Majority (60\% of fathers and $66.7 \%$ of mothers) would seek eye examination for their children only when the child has an eye complain or eye problem. The belief that routine eye exam is not necessary was reported as the major barrier in seeking eye examination for their children $(60 \%$ of fathers and $57 \%$ of mothers). Other barriers include funds, time, the use of traditional medicine, and distance to eye clinic. Over $65 \%$ of parents would allow their children use any eye treatment at any age as long as the doctor states the necessity. Although, few parents would restrict their children from the use of glasses, eye surgery and eye training until the child is 10 years. Fathers were significantly $(\mathrm{p}=0.008)$ better educated about the eyes than mothers although, less than $30 \%$ of respondents has had education about eye care. Less than $1 \%$ of respondents know that a child is old enough to have a comprehensive eye examination at 6 months. Conclusion: Proper parent education and enlightenment strategies should be put in place by professional bodies and the government to make better parents attitude towards eye examination for the sake of an improved eye health for children.

Keywords: Parents, Eye examination, Eye treatment, Children

\section{Introduction}

The visual system of children is immature when born. For normal vision development to occur, images transmitted to the higher centers must be clear and properly focused. A failure in vision development may occur unnoticed unless there is an eye examination. This could result in reduced vision which may be difficult to correct. ${ }^{1}$

Blindness in children can be avoidable with preventive measures and when eye examination and treatment is early and frequent. In the developed world, children are required to undergo eye examination at birth and as 
early as six months. By six months an average child has attained a number of developmental milestones and so can undergo a full eye examination. Afterwards, a comprehensive eye examination is necessary at the preschool age and frequently during the school age. ${ }^{2}$ School visual screening is not sufficient but regular comprehensive eye examination at intervals.

A variety of factors can cause severe visual impairment and blindness in children, the leading source has been linked to corneal scarring, ${ }^{3}$ caused by vitamin A deficiency and measles followed by cataract and retinopathy of prematurity. In addition to the correction of significant refractive errors and provision of low vision services, the vision 2020 program has given priority to the control of these conditions mentioned above. ${ }^{1}$

Childhood blindness accounts for $3.2 \%$ of the burden of global blindness. ${ }^{4}$ Though the number of cases of blindness and visual impairment in children is lower than in adults, Childhood blindness and visual impairment control have been prioritized by the World Health Organization (WHO) for some reasons. Firstly, most causes of blindness in children are avoidable ${ }^{5}$ and elimination will greatly reduce the prevalence of blindness in countries of low income like sub-Saharan Africa and Asia. ${ }^{1}$ Secondly, childhood blindness is closely related to mortality rate $^{1,6}$ and $60 \%$ of children who go blind from conditions like premature birth, measles, congenital rubella syndrome, vitamin A deficiency and meningitis die within a year of going blind. Thirdly, Even if a blind child survives, his number of blind years ahead is very high, ${ }^{1,7}$ causing blindness to have more devastating effect in children. These children may pose an emotional and socio economic challenge for their families, they may be less likely to complete their education and hence make a living for themselves.

To actualize this priority, early and regular eye examination in children is a very important tool for ensuring normal visual development and reduce the risk of vision loss, facilitating early detection and treatment, consultation by another eye care practitioner or referral where necessary. Health education of parents and guardians on the need for frequent eye examination and necessary treatment is an important WHO strategy in developing countries where a good number of people have poor knowledge of the importance of eye examination and treatment, hence neglecting eye care for their children. ${ }^{8}$

Ntsoane and Oduntan, $(2010)^{9}$ enumerated a number of demographic factors that could affect the utilization of eye care facilities these include age, gender, level of education, race, socio economic factors, knowledge of eye diseases and eye care services. Furthermore, barriers to parents seeking eye examination for their children may include the belief that eye examination is not necessary, ${ }^{10}$ lack of funds, ${ }^{11,12}$ distance from eye clinic, time, reliance on pediatricians, general practitioners and visual screenings ${ }^{2}$ and the availability of traditional medicine as a cheaper alternative. ${ }^{13}$

There is no operational government protocol that makes pediatric vision examination necessary at different ages in Nigeria. Hence, we sought to find out parents' knowledge and attitude towards children eye examination and treatment and the effect of demographic factors such as gender, age, educational status and number of children. This could serve as source of information guiding children-oriented parent eye-health-education messages.

\section{Materials and method}

This cross-sectional observational survey was carried out in Benin City. Benin city, the capital of Edo state has 2 major hospitals which run an eye clinic, the University of Benin optometry department eye clinic at 2 campuses, and about 20 Private eye clinics/hospitals. Asemi-structured questionnaire was distributed using convenience sampling technique to 600 parents (not necessarily couples) with at least a child less than 16 years of age. The questionnaire was pretested amongst 4 fathers - 2 educated and 2 uneducated and 4 mothers - 2 educated and two uneducated in Benin city, restructured for easy understanding and thereafter shared at social meetings, church gatherings and work places around Benin city. Distribution of the final questionnaires was by hand. The questionnaires were self-administered for most educated parents but interview administered for those who requested.

Four hundred and sixty eight (78\%) properly filled questionnaires were retrieved for this study. Each questionnaire had three major sections: section one assessed the parents' attitude towards eye examination and barriers to seeking routine eye care for their children, section two assessed parents' attitude towards eye treatment for their child and section three assessed parents' knowledge on eye care.

Parents attitude were judged based on their response to either of the following as regards seeking eye examination for their children; routine eye examination, referral by a general medical practitioner or pediatrician, presence of eye complain or problem and other reasons such as accidents or ocular emergencies. They were further asked a question to elicit barriers faced by them to routine eye examination and in addition eye conditions that would require them to seek eye examination. Parents were also made to indicate at what ages they can allow their child to use these form of eye treatment; eye drop, eye ointment, glasses, eye surgery and eye training.

As regards how much they know about eye care, parents were asked to pick from the following options where they have had information about care of the eyes; radio, television, personal studies, seminars and lectures, hospital, personal studies, journals. They were also asked if they know that a child should have his first comprehensive eye examination by 6 months.

Statistical package for social sciences (SPSS version 22) was used to represent the data in tables and figures and the test of significance was performed at $p<0.05$ using Chi square test. This study faced limitations due to recall bias as with a typical questionnaire study. 


\section{Results}

Of the 468 respondents, $196(41.88 \%)$ were males and $272(58.12 \%)$ were females, within the ages 21-65 years; majority were aged between $31-50$ years, 359 $(76.71 \%)$. Out of the 260 females who indicated their educational status, majority (125) $48 \%$ had Secondary School leaving certificate as their highest level of education while,61 (33\%) out of the 186 males indicated they had been to one higher institution or the other. Most parents, (60\% females and $67 \%$ males) in Benin City have 1-3 children, while few parents ( $4 \%$ females and $6 \%$ males) have greater than 6 children. There were no significant associations between parents' attitude to eye examination and age $(p=0.920$ for fathers, and $p=0.890$ for mothers), educational status $(p=0.309$ for fathers, $\mathrm{p}=0.949$ for mothers), and number of children ( $\mathrm{p}=0.0787$ for fathers and $\mathrm{p}=0.544$ for mothers).

Few parents (6\% of fathers, and $4.1 \%$ of mothers) recognize routine eye examination as a reason to seek eye examination for their children, majority (60\% of fathers and $66.7 \%$ of mothers) would seek eye examination for their children only when the child has an eye complain or eye problem. Twenty-six percent of fathers would seek eye examination for their child if a general medical practitioner or pediatrician refers their children to see an eye care practitioner for a comprehensive eye examination. Other reasons why parents would seek eye examination for their children includes accidents and ocular emergencies. This difference amongst the response from fathers and mothers was seen to be significant $(\mathrm{p}=0.003)$.

Fig 1: Reasons why parents seek eye examination for their children

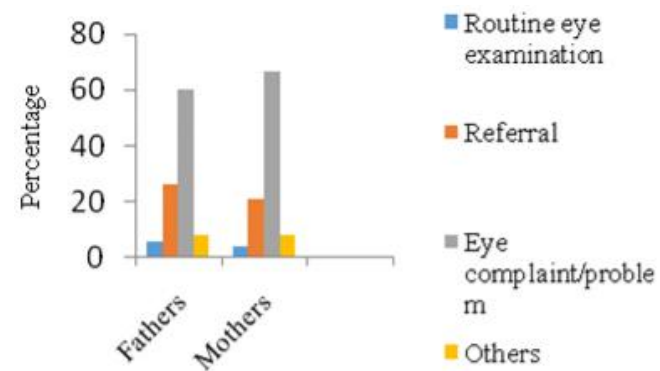

\begin{tabular}{|c|c|c|c|c|c|}
\hline & $\begin{array}{l}\text { Routine eye examination } \\
\text { Frequency }(\%)\end{array}$ & $\begin{array}{l}\text { Doctor's referral } \\
\text { Frequency }(\%)\end{array}$ & $\begin{array}{l}\text { Eye complaint } \\
\text { Frequency }(\%)\end{array}$ & $\begin{array}{l}\text { Others } \\
\text { Frequency (\%) }\end{array}$ & $P$ - value \\
\hline \multicolumn{6}{|l|}{ Age (fathers) } \\
\hline $21-25$ & $0(0)$ & $0(0)$ & $0(0)$ & $0(0)$ & \multirow{10}{*}{0.9020} \\
\hline $26-30$ & $0(0)$ & $2(33)$ & $4(66)$ & $0(0)$ & \\
\hline $31-35$ & $3(8)$ & $7(19)$ & $24(65)$ & $3(8)$ & \\
\hline $36-40$ & $2(9)$ & $7(32)$ & $12(55)$ & $1(4.5)$ & \\
\hline $41-45$ & $3(6)$ & $10(21)$ & $30(61)$ & $6(12)$ & \\
\hline $46-50$ & $2(5)$ & $14(36)$ & $19(49)$ & $4(10)$ & \\
\hline $51-55$ & 1(4) & $6(24)$ & $18(72)$ & $0(0)$ & \\
\hline $56-60$ & $1(7)$ & $4(29)$ & $9(64)$ & $0(0)$ & \\
\hline $61-65$ & $0(0)$ & $1(25)$ & $3(75)$ & $0(0)$ & \\
\hline Total & $12(6)$ & $51(26)$ & $119(60)$ & $14(8)$ & \\
\hline \multicolumn{6}{|l|}{ Age (mothers) } \\
\hline $21-25$ & $0(0)$ & $3(37.5)$ & $5(62.5)$ & $0(0)$ & \multirow{10}{*}{0.890} \\
\hline $26-30$ & $1(3.7)$ & $8(29.6)$ & $16(59.2)$ & $2(7.4)$ & \\
\hline $31-35$ & $2(4.9)$ & $7(17.1)$ & $28(68.2)$ & $4(9.8)$ & \\
\hline $36-40$ & $4(4.9)$ & $14(17.1)$ & $56(68.2)$ & $8(9.8)$ & \\
\hline $41-45$ & $1(2.4)$ & $10(24.4)$ & $30(73.1)$ & $0(0)$ & \\
\hline $46-50$ & $2(4.3)$ & $8(19.5)$ & $30(65.2)$ & $6(13)$ & \\
\hline $51-55$ & $1(4.5)$ & $6(27.3)$ & $13(59.1)$ & $2(9.1)$ & \\
\hline $56-60$ & $0(0)$ & $0(0)$ & $0(0)$ & $0(0)$ & \\
\hline $61-65$ & $0(0)$ & $0(0)$ & $0(0)$ & $0(0)$ & \\
\hline Total & $11(4.1)$ & $56(21.0)$ & $178(66.7)$ & $22(8.2)$ & \\
\hline \multicolumn{6}{|c|}{ Number of children (fathers) } \\
\hline $1-3$ & $10(7.9)$ & $28(22)$ & $82(64.6)$ & $7(5.5)$ & \multirow{4}{*}{0.787} \\
\hline $4-6$ & $7(12.3)$ & $17(29.8)$ & $31(54.4)$ & $2(3.5)$ & \\
\hline$>6$ & $0(0)$ & $2(33.3)$ & $4(66.7)$ & $0(0)$ & \\
\hline Total & $17(9.0)$ & $47(24.7)$ & $117(61.6)$ & $9(4.7)$ & \\
\hline \multicolumn{6}{|c|}{ Number of children (mothers) } \\
\hline $1-3$ & $8(4.9)$ & $30(18.4)$ & $115(70.6)$ & $10(6.1)$ & \multirow{4}{*}{0.544} \\
\hline $4-6$ & $10(10.2)$ & $18(18.4)$ & $66(67.3)$ & $4(4.1)$ & \\
\hline$>6$ & $1(9.1)$ & $3(27.3)$ & $6(54.5)$ & $1(9.1)$ & \\
\hline Total & $19(6.9)$ & $51(18.8)$ & $187(68.8)$ & $15(5.5)$ & \\
\hline \multicolumn{6}{|c|}{ Educational status (fathers) } \\
\hline No Education & $0(0)$ & $2(33.3)$ & $4(66.6)$ & $0(0)$ & \multirow{6}{*}{0.309} \\
\hline Primary & $0(0)$ & $5(29.4)$ & $11(64.7)$ & $1(5.9)$ & \\
\hline WAEC & $2(3.8)$ & $10(19.2)$ & $40(76.9)$ & $0(0)$ & \\
\hline Vocation & $2(4)$ & $15(30)$ & $28(56)$ & $5(10)$ & \\
\hline Higher institution & $6(8.5)$ & $12(16.9)$ & $50(70.4)$ & $3(4.2)$ & \\
\hline Total & $10(5)$ & $45(22.8)$ & $133(67.5)$ & $9(4.6)$ & \\
\hline \multicolumn{6}{|c|}{ Educational status (mothers) } \\
\hline No Education & $0(0)$ & $1(20)$ & $4(80)$ & $0(0)$ & \multirow{6}{*}{0.949} \\
\hline Primary & $1(3.2)$ & $8(25.8)$ & $20(64.5)$ & $2(6.5)$ & \\
\hline WAEC & $2(1.6)$ & $25(20)$ & $88(70.4)$ & $10(8)$ & \\
\hline Vocation & $1(1.9)$ & $15(28.9)$ & $34(65.4)$ & $2(3.8)$ & \\
\hline Higher institution & $2(4.3)$ & $10(21.3)$ & $30(63.8)$ & $5(10.6)$ & \\
\hline Total & $6(2.3)$ & $59(22.7)$ & $176(67.7)$ & $19(7.3)$ & \\
\hline
\end{tabular}


Barriers to seeking routine eye care

The belief that routine eye exam is not necessary was reported as the major barrier in seeking routine eye examination for their children $(60 \%$ of fathers and $57 \%$ of mothers). Other barriers include funds, time, the use of traditional medicine, and distance to eye clinic (Fig 2).

Fig 2: Barriers reported by parents to routine eye examination of their children

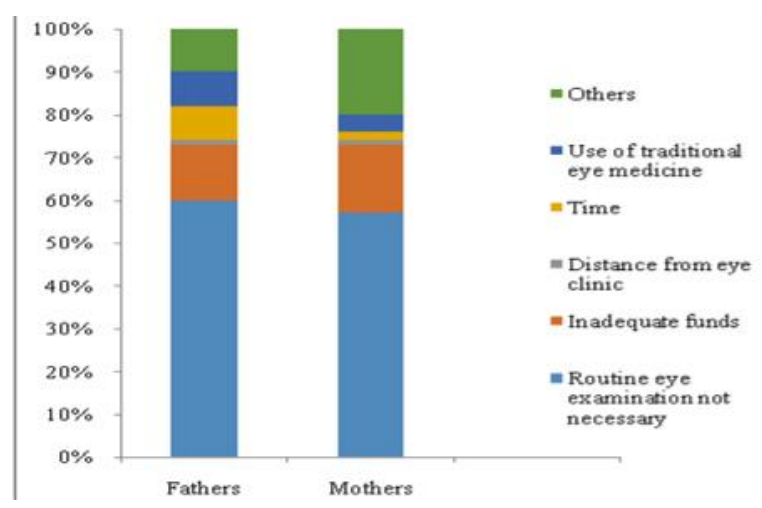

Conditions causing parents to seek eye exam for their children

Over $60 \%$ of fathers will seek eye examination for their children if the eye complaint is squint or eye pain and discomfort. No father agreed to frequent headaches as a possible vision problem necessitating them to seek eye examination for their children.

Other than squint, eye pain and discomfort, $19 \%$ of mothers will seek eye examination for their children for other reasons such as ocular emergencies.

Fig 3: Reasons why fathers seek an eye exam for their children

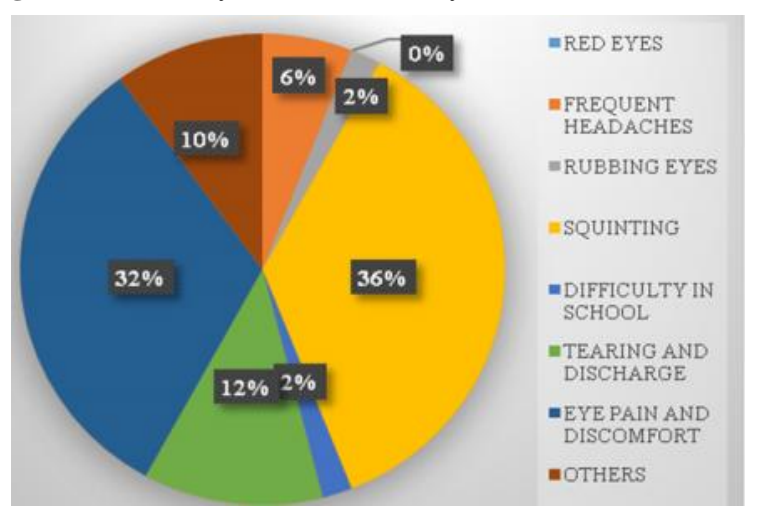

Fig 4: Reasons why mothers seek an eye exam for their children

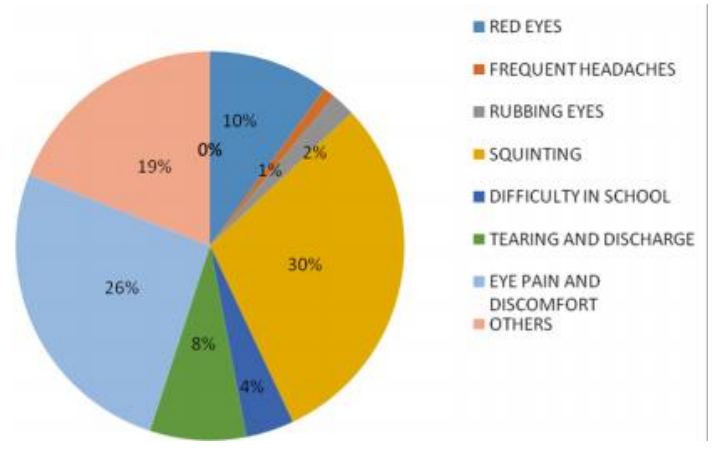

\section{Eye treatment}

Over $65 \%$ of parents would allow their children use any eye treatment at any age as long as the doctor states the necessity. Figures 3 and 4 show Parents' attitude towards eye treatments for their children. This difference was found to be statistically significant $(p=0.00)$.

Fig 5: The use of various eye treatments for children reported by fathers

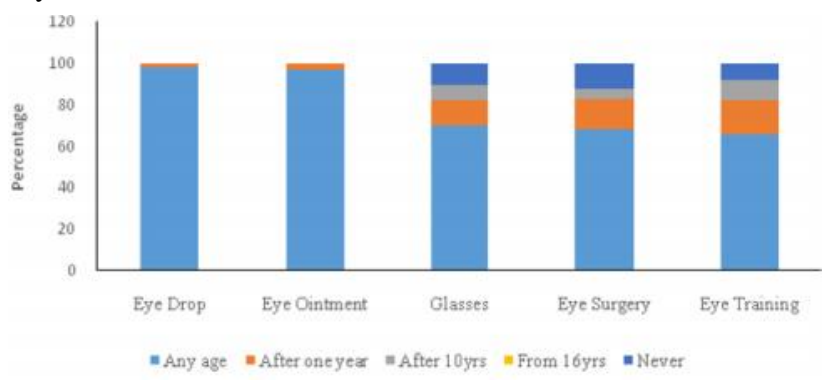

Fig 6: The use of various eye treatments for children reported by mothers

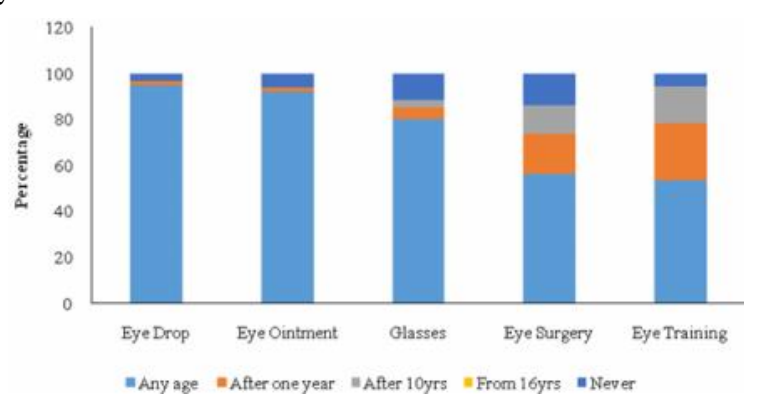

Knowledge about the eyes

The question on parents' acquisition of knowledge about the eye was answered by 426 parents (240 mothers and 186 fathers). From the result, less than one third claim to have had knowledge about eye care.

Fathers were significantly $(\mathrm{P}=0.008)$ better educated about the eyes than mothers, $48(25.8 \%)$ fathers claim they have had education about the eyes from various sources compared to only $37(15.4 \%)$ mothers. This information is shown in Table 3 below.

\begin{tabular}{lll}
\hline \multicolumn{2}{l}{ Table 3: Parents' } & \multicolumn{2}{c}{ sources of knowledge about the eyes } \\
& Fathers & Mothers \\
\hline Radio & 4 & 7 \\
TV & 28 & 16 \\
Hearsay & - & 3 \\
Personal studies & 11 & 4 \\
Journals & 3 & 2 \\
Others & 2 (seminars and & 5 (Hospitals) \\
& lectures) & \\
Total & 48 & 37 \\
\hline
\end{tabular}

When asked if they are aware that a child should have his first comprehensive eye examination at 6 months, only $3(0.64 \%)$ indicated 'Yes' while the rest reported 'No'. 
Table 2: Demographic characteristics of parents as it relates to knowledge about the eye

\begin{tabular}{|c|c|c|c|}
\hline \multirow{2}{*}{$\begin{array}{l}\text { Have you had any } \\
\text { form of education } \\
\text { about the eyes? }\end{array}$} & Yes & No & \multirow[t]{2}{*}{$P$ - value } \\
\hline & Frequency (\%) & Frequency(\%) & \\
\hline \multicolumn{4}{|l|}{ Age (fathers) } \\
\hline $21-25$ & - & - & \multirow{10}{*}{$<0.0001$} \\
\hline $26-30$ & - & $6(100)$ & \\
\hline $31-35$ & $21(56.8)$ & $16(43.2)$ & \\
\hline $36-40$ & $26(100)$ & - & \\
\hline $41-45$ & $48(100)$ & - & \\
\hline $46-50$ & $39(100)$ & - & \\
\hline $51-55$ & $25(100)$ & - & \\
\hline $56-60$ & $14(100)$ & - & \\
\hline $61-65$ & $4(100)$ & - & \\
\hline Total & 213(90.6) & $22(9.4)$ & \\
\hline \multicolumn{4}{|l|}{ Age (mothers) } \\
\hline $21-25$ & $3(37.5)$ & $5(62.5)$ & \multirow{10}{*}{0.200} \\
\hline $26-30$ & $9(33.3)$ & $18(66.7)$ & \\
\hline $31-35$ & - & $37(100)$ & \\
\hline $36-40$ & $6(9.8)$ & $55(90.2)$ & \\
\hline $41-45$ & $11(35.5)$ & $20(64.5)$ & \\
\hline $46-50$ & $35(76.1)$ & 11(23.9) & \\
\hline $51-55$ & $5(22.7)$ & $17(77.3)$ & \\
\hline $56-60$ & $1(20)$ & $4(80)$ & \\
\hline $61-65$ & - & - & \\
\hline Total & $70(25.6)$ & $203(74.4)$ & \\
\hline \multicolumn{4}{|c|}{ Number of children (fathers) } \\
\hline $1-3$ & $95(81.9)$ & $21(18.1)$ & \multirow{4}{*}{--} \\
\hline $4-6$ & $56(100)$ & - & \\
\hline$>6$ & $5(100)$ & - & \\
\hline Total & $156(88.1)$ & 21(11.9) & \\
\hline \multicolumn{4}{|c|}{ Number of children (mothers) } \\
\hline $1-3$ & $22(10.4)$ & 189(89.6) & \multirow{4}{*}{0.054} \\
\hline $4-6$ & $42(47.2)$ & $47(52.8)$ & \\
\hline$>6$ & $3(20)$ & $12(80)$ & \\
\hline Total & $94(27.5)$ & $248(72.5)$ & \\
\hline \multicolumn{4}{|c|}{ Educational status (fathers) } \\
\hline No Education & $6(100)$ & - & \multirow{6}{*}{0.369} \\
\hline Primary & $15(93.8)$ & $1(6.2)$ & \\
\hline WAEC & $47(90.4)$ & $5(9.6)$ & \\
\hline Vocation & $43(86)$ & $7(14)$ & \\
\hline Higher institution & $50(86.2)$ & $8(13.8)$ & \\
\hline Total & $161(88.5)$ & $21(11.5)$ & \\
\hline \multicolumn{4}{|c|}{ Educational status (mothers) } \\
\hline No Education & $3(75)$ & $1(25)$ & \multirow{6}{*}{0.002} \\
\hline Primary & $16(61.5)$ & $10(38.5)$ & \\
\hline WAEC & $48(35.6)$ & $87(64.4)$ & \\
\hline Vocation & $2(3.8)$ & $50(96.2)$ & \\
\hline Higher institution & $11(22)$ & $39(78)$ & \\
\hline Total & $80(30)$ & 187(70) & \\
\hline
\end{tabular}

\section{Discussion}

The purpose of this work was to find out the knowledge and attitude of parents in Benin City as regards eye examination and treatment for their children. Of the four demographic factors assessed by this study, only gender significantly affected parents' attitude toward eye examination for children. This difference in response may be attributed to the significant difference in parents' knowledge about the eyes. Although one will expect mothers to have better education about the eyes than fathers due to the fact that they visit the hospital with the children more often than fathers and are likely to get health information about their children from there, but in a society where the health sector does not do much to educate parents about routine eye checkup for children, mothers are deprived of such information.

From this study, routine children eye examination was not subscribed to by most parents, this was a similar finding in a previous study. ${ }^{10}$ However, this contradicts the conclusion from Ayanniyi et al., (2010) ${ }^{8}$ that parents had the right perception to the eye care of their children. The contradiction results from the study's focus on guardians' eye care seeking behavior when a child has an eye problem or complain alone, which is different from this study that assessed routine eye examination and treatment among other reasons.

Funds were also a major barrier for both fathers and mothers as expected from a low-income countries, this has been previously identified by other studies, ${ }^{9,11,12,14}$ Although guardians/parents economic status and their choices in managing children's ocular condition was not investigated. Time and traditional medicine availability were also barriers seen more amongst fathers, inadequate time reported may be because most fathers are the bread winners of the family hence they feel their role ends with provision of money and they have less time to seek eye examination for their children. Distance to eye clinic was the least reported, this may be because of the good distribution of eye clinics in Benin metropolis or the notion that if a child has a need for eye examination and the money is available then distance will not be a hindrance.

Majority of parents reported that their children could use any treatment for the eyes as long as a doctor has prescribed it. This is good, as parents rely on doctor's judgment more than their personal beliefs. Also few parents indicated restricting their children from the use of glasses, eye surgery and eye training until the child is 10 years. Some parents, mostly mothers who claimed their child will never have any form of eye treatment and nothing to do with eye clinic do this because of their beliefs and misconceptions about eye conditions and treatments and probably as a result of religious bias. The few children who are allowed to go without eye treatment due to restrictions from their parents could add significantly to the socioeconomic burden arising from children who are visually impaired in our society.

\section{Authors' contribution}

OMA: Study conception and design, manuscript preparation.

DCA: Manuscript editing, ensured proper referencing and provided educational guidance and counseling.

IA: Data collection and analysis

Conflict of interest: None

Funding: None 


\section{References}

1. Gilbert C, Foster A. Childhood blindness in the context of vision 2020 - the right to sight. Bull World Health Organ. 2001; 79(3): 227-232.

2. American Optometric Association. Optometric clinical practice guideline, Pediatric eye and vision examination. Reference guide for clinicians. St. Louise, MO: AOA, 2002.

3. Preventing blindness in children. Report of a WHO/IAPB scientific meeting. Hyderabad, India. 2000; WHO/PBL/00.77.

4. WHO, vision 2020, the right to sight. Global initiative for the elimination of avoidable blindness. Action plan 2006 - 2011. htt:// www.who.int/blindness/ vision2020\%20-report.pdf. Accessed online on 22/10/2015.

5. Titiyal JS, Pal N, Murthy GVS, Gupta SK, Tandon R, Vajpayee RB. Causes and temporal trend on blindness and severe visual impairment in children in schools for the blind in North India. $\mathrm{Br} \mathrm{J} \mathrm{Op}$ thamol.2003; 87: 941-945.
6. Adio AO, Komolafe RD. The State of Pediatric Eye Care in Nigeria: A Situational Review and Call for Action. Nig Health J. 2013; 13(1): 2-4.

7. Gilbert C. New Issues in childhood blindness. Comm Eye Health.2001; 14(40): 53-56.

8. Ayanniyi AA, Olatunji FO, Mahmoud AO, Ayanniyi RO. Knowledge and Attitude of Guardians towards Eye Health of Primary School Pupils in llorin, Nigeria. Nig. Postgrad Med. J. 2010; 17(1): 1-4.

9. Ntsoane MD, Oduntan OA. A review of factors influencing the utilization of eye care services. $S$ Afr. Optom. 2010; 69(4): 182-192.

10. Ramai D, Pulisetty T. Maternal and Caregiver Perceptions to Childhood Eye Care In Ghana. Internet J Epidem. 2013; 11(1): 28.
11. Balasubramaniam SM, Kumar DS, Kumaran SE, Ramani KK. Factors affecting eye care - seeking behavior of parents for their children. Optom Vis Sci. 2013; 90 (10): 1138-42.

12. Kovai V, Krishnaiah S, Shamanna BR, Thomas R, Rao GN. Barriers to accessing eye care services among visually impaired populations in rural Andhra Pradesh, South India. Indian J. Ophthalmol. 2007; 55: 365-371.

13. AmiebenomoOM, Amiebenomo HO, Emadamerho OL. A hospital based study of traditional eye medicines usage in Benin City, Edo State. J Nig Optom Assoc. 2014; 19(1): 12-16.

14. Chipendo GN, January J, Tapera R, Dube B. Community perceptions of eye diseases among 1440 year olds in Chiota, Zimbabwe. Educ. Res. 2012; 3: 780784 . 